\title{
Phase Encoding in the Mauthner System: Implications in Left-Right Sound Source Discrimination
}

\author{
Shennan A. Weiss, Thomas Preuss, ${ }^{\star}$ and Donald S. Faber* \\ Dominick P. Purpura Department of Neuroscience, Albert Einstein College of Medicine, Bronx, New York 10461
}

\begin{abstract}
The paired teleost Mauthner (M)-cells and their associated network serve as an excellent system to study the biophysical basis of decision making. In teleosts, an abrupt sound evokes an M-spike, triggering a C-start escape that is usually directed away from a sound source. The response latency is minimized by electrical synapses between auditory afferents and the M-cell lateral dendrite. Here, we demonstrate that the electrical synapses also mediate phase encoding. Ramped sound pressure waves $(150-250 \mathrm{~Hz})$ evoked electrotonic postsynaptic potentials in the M-cell locked to two diametrically opposed phase angles that were frequency dependent but intensity independent. Phase encoding was also evident at the behavioral level underwater, because the stimuli evoked directional C-starts with an onset that was phase locked to the sound wave. In interneurons inhibitory to the M-cell, these same stimuli also evoked phase-locked electrotonic postsynaptic potentials and action potentials. The resulting chemical and electrical (i.e., field effect) inhibitions functioned tonically and phasically, respectively. Phase encoding could be important in underwater sound source localization, which is thought to require a neural computation involving a phase comparison between the pressure and the directional particle motion components of sound. This computation may be implemented by an interplay between phase-dependent afferent excitation and feedforward inhibition that activates the appropriate $\mathrm{M}$-cell and directs the $\mathrm{C}$-start away from the sound source.
\end{abstract}

\section{Introduction}

Understanding the biophysical basis of computations in single neurons is critical to understanding brain function (Koch, 1999). To this end, the teleost Mauthner (M)-cell is an ideal model because an action potential in one of the paired M-cells initiates the C-start escape behavior (Zottoli, 1977; Eaton et al., 1981; Weiss et al., 2006). Furthermore, the representation of stimulus features in the membrane potential trajectory of the M-cell dictates escape timing (Preuss et al., 2006). A hallmark of the escape evoked by an abrupt acoustic stimulus is its short latency, attributable to electrotonic synapses between auditory afferents and the M-cell (Szabo et al., 2006). Additionally, such synapses can subserve the accurate preservation of temporal information (i.e., time coding) and permit temporal comparisons that can mediate neuronal computations (Carr and Friedman, 1999).

A problem faced by the $\mathrm{M}$-cell system is distinguishing the general location of a sound stimulus, because the C-start is usually directed away from the source (Blaxter et al., 1981; Preuss and Faber, 2003). This implies that membrane potential changes in the two M-cells should represent sounds from the right and left asymmetrically. A previously proposed hypothesis concerning how this occurs is based on the phase model of directional hearing in fish (Schuijf, 1975). This model theorizes that the axis of

\footnotetext{
Received June 26, 2008; revised Jan. 12, 2009; accepted Feb. 4, 2009.

This work was supported by National Institute of Neurological Disorders and Stroke Grant 1F30NS059154-01 (S.A.W.). We thank Drs. Michael V. L. Bennett, Alberto Pereda, and Jose Luis Pena for their assistance with this study. ${ }^{*}$ T.P. and D.S.F. contributed equally to this work.

Correspondence should be addressed to Dr. Donald S. Faber, Department of Neuroscience, Albert Einstein College

of Medicine of Yeshiva University, 1300 Morris Park Avenue, Bronx, NY 10461. E-mail: dfaber@aecom.yu.edu. D0I:10.1523/JNEUROSCI.3383-08.2009

Copyright $\odot 2009$ Society for Neuroscience $\quad 0270-6474 / 09 / 293431-11 \$ 15.00 / 0$
}

the particle motion component of sound is detected by a broad array of specifically oriented hair cells in the otolith end organs (Hudspeth and Corey, 1977; Fay, 1984). The unambiguous resolution of the azimuth of the sound source, however, theoretically requires a phase comparison between sound particle motion and pressure, the two physical components of sound. Eaton et al. (1995) postulated this comparison occurs in the M-cell system, because the C-start is directed away from both abrupt initially compressing and rarifying sound pulses (Fig. 1A) (Canfield and Rose, 1996).

The M-cell is primarily excited by sound pressure amplified by the swim bladder and transduced by the sacculus (Fig. $1 \mathrm{~B}$ ) (Canfield and Eaton, 1990). Ipsilateral saccular nerve fibers terminate as large myelinated club endings that have mixed electrical and chemical synapses on the lateral dendrite (Tuttle et al., 1986; Pereda et al., 2003). Bilateral saccular afferents also excite feedforward inhibitory neurons (Zottoli and Faber, 1980; Triller and Korn, 1981). Action potentials in the axon terminals of the latter result in electrical inhibition of the $\mathrm{M}$-cell axon hillock (Furukawa and Furshpan, 1963; Korn and Faber, 1975), a field effect (Faber and Korn, 1989; Jefferys, 1995), and it is succeeded by chemical inhibition because of the release of glycine (Korn and Faber, 1976).

A critical component of the phase model is that phase information be preserved in the responses of the M-cell system. We show here with ramped sinusoidal sounds (Szabo et al., 2006) that the timing of the $\mathrm{C}$-start onset is phase locked. Furthermore, when these stimuli are applied in air to simulate the pressure component underwater, both electrical excitation and inhibition of the M-cell are phase locked to the stimulus. Thus, excitatoryinhibitory integration may discriminate left-right sound sources in the M-cell. 


\section{Materials and Methods}

Adult goldfish, $5-20 \mathrm{~cm}$ in body length, were maintained as previously described (Preuss and Faber, 2003).

In vivo electrophysiology. Fish were immobilized with D-tubocurarine ( $1 \mathrm{mg} / \mathrm{g}$ body weight) and anesthetized with continuous perfusion of conditioned water $\left(18^{\circ} \mathrm{C}\right)$ containing $60 \mathrm{mg} / \mathrm{L}$ MS-222 (3-aminobenzoic acid ethyl ester) (Sigma-Aldrich). The fish was restrained and the midbrain was exposed as described previously (Furukawa and Furshpan, 1963). Micropipettes filled with $5 \mathrm{~m}$ KAc (resistances, $\sim 3-5 \mathrm{M} \Omega$ ) or $3 \mathrm{M} \mathrm{KCl}(8-30 \mathrm{M} \Omega$ ) were used to record intracellularly from the M-cell or inhibitory [passive hyperpolarizing potential (PHP)] neurons, respectively. EMG electrodes were prepared as previously described (Weiss et al., 2006). Computer-generated exponentially ramped sound waves and single cycle sinusoids (pips) were amplified (Servo 120; Samson) and produced by a studio monitor (JBL Pro 4410) situated in the far field $\sim 2.1 \mathrm{~m}$ from the head of the fish in a room with acoustic foam to prevent reverberation. The stimulus was recorded with a microphone (model 4190 free-field 1/2"; Brüel \& Kjær) located in the position of the fish. Data were recorded on-line with a Macintosh G4 using acquisition software developed in the laboratory for Igor Pro (Wavemetrics) at a sampling interval of $40 \mu$ s and analyzed with the same software and Labview 7 (National Instruments).

For strychnine iontophoresis, a glass micropipette was filled with $18.5 \mathrm{~mm}$ strychnine sulfate (Sigma-Aldrich) in $2.5 \mathrm{M} \mathrm{KCl}$ (resistance, $\sim 2 \mathrm{M} \Omega$ ), and was positioned near the axon cap of the M-cell, as determined by an extracellular antidromic M-spike height between 3 and $5 \mathrm{mV}$ in the negative direction. Iontophoretic currents were $-100 \mathrm{nA}$ in magnitude, with variable duration. To confirm that strychnine had bound to the glycine receptors on the M-cell, we asked whether the magnitude of the glycinergic collateral IPSP in the M-cell soma, evoked by antidromic (AD) stimulation, was reduced in amplitude (Faber and Korn, 1989). Because the reversal potential of the chloride conductance is close to resting potential of the M-cell, the magnitude of the collateral IPSP can be determined using paired AD stimuli. The first stimulus elicits a full sized M-spike, followed by the collateral IPSP and the second stimulus elicits an M-spike that is shunted by the inhibitory conductance. The magnitude of the inhibitory conductance, $G_{\text {ipsp }}$, can be calculated as the ratio of the amplitudes of the two M-spikes, $V$ and $V^{\prime}$, respectively, by the formula $G_{\text {ipsp }} / G_{\mathrm{m}}=\left(V / V^{\prime}\right)-1$, where $G_{\mathrm{m}}$ is the previously characterized membrane conductance (Faber and Korn, 1982). This calculation is based on the assumption that the $\mathrm{M}$-spike can be treated as a constant current source.

Behavioral experiments. Behavioral experiments were performed as previously described (Preuss and Faber, 2003; Weiss et al., 2006). Briefly, the circular experimental aquarium had a diameter of $76 \mathrm{~cm}$ and a water depth of $28 \mathrm{~cm}$. Temperature was maintained at $18^{\circ} \mathrm{C}$. Sound stimuli were produced by one of two underwater loud speakers (UW-30; University Sound) at the outer circumference of the tank. The pressure component of an auditory stimulus was recorded with a hydrophone (SQ01; Sensor Technology). Ventral views of freely swimming fish were recorded at 1000 frames/s and at a spatial resolution of 512 by 384 pixels through a mirror at $45^{\circ}$ below the tank, using two high-speed video cameras (Kodak Extapro 1000 HRC; Eastman Kodak). Directionality was assessed when the fish was more than one to two body lengths away from the sound source and situated in a relatively parallel orientation with respect to the speaker. EMGs were amplified with a four-channel differential AC amplifier (model 1700; A-M Systems) and bandpass filtered from $10 \mathrm{~Hz}$ to $20 \mathrm{kHz}$ and from $300 \mathrm{~Hz}$ to $10 \mathrm{kHz}$, respectively.

Data analysis and calculations. The peak times for individual fast EPSPs, action potentials, and extracellular fields associated with firing of the inhibitory interneurons, the so-called extrinsic hyperpolarizing potentials (EHPs) (Furukawa and Furshpan, 1963), were calculated using a peak detection algorithm that is based on a quadratic fit of a specified width $(>200 \mu \mathrm{s})$ and threshold level $(0.25 \mathrm{mV})$. To isolate the EPSPs, 
and EHPs, they were first high-pass filtered using a sixth-order Butterworth filter with a high-pass cutoff of 60 and $10 \mathrm{~Hz}$, respectively. To calculate the phase angle of the EPSPs, action potentials, EHPs, and the EMG onset time, with respect to the sound stimulus, it was first necessary to calculate the sound wave stimulus phase function $\theta(t)$ using an instantaneous phase decomposition method. We calculated the analytic signal of the sound stimulus $s(t)=s_{r}(t)+i s_{i}(t)$, where $s_{r}(t)$ is the sound stimulus, $s_{i}(t)$ is the Hilbert transform of $s_{r}(t)$, and $i=V-1$. The analytic signal was then converted to polar form [i.e., $s(t)=r(t) e^{i * \theta(t)}$ ] (Smith et al., 2002). The function $r(t)$ describes the stimulus amplitude envelope that was used for peak sound pressure level (SPL) calculations

In the case of the fast EPSPs, action potentials, and EHPs, the phase distributions were clearly bimodal in most cases. They were thus split into two evenly spaced distributions by first visually approximating the primary mean phase angle. All the events were then assigned to one of the two distributions. The visual estimate was aided by a polar plot, and phase histogram of the fast EPSP events. Polar representations of events are characterized by phase angle and vector length, which corresponds to the event amplitude. In addition, the vector strength (VS) is a measurement of coherence for a population of events. The mean phase angles of the primary and secondary distributions and VS were identified by calculating the first trigonometric moment using the equation $m^{\prime}=(1 /$ $\left.\Sigma A_{i}\right)^{*} \Sigma A_{i} e^{i *} \phi_{i}=R e^{i * \theta}$, where $A_{i}$ and $\phi_{i}$ are the vector length in millivolts and the phase angle of each event, respectively, and $R$ and $\theta$ are the resulting VS and mean phase angle, respectively (Fisher, 1993). Action potentials were equally weighted. A VS value of 1 indicates perfect coherence. Calculation of mean phase angle and vector length was also performed by vector addition in Euclidean space.

To further statistically describe phase locking, we used the omnibus modified Kuiper's $V$ test for randomness against any alternative, and Rayleigh's test for circular uniformity. When the $V$ test was used to evaluate the phase angles of the fast EPSP events, the threshold for peak detection was increased to $0.5 \mathrm{mV}$ to increase the signal-to-noise ratio, which was required because the vectors were unweighted. Rayleigh's test for circular uniformity was calculated as $Z=n R^{2}$. The probability that the null hypothesis of sample uniformity holds, for $n>50$, was estimated as $p=e^{-Z}$. The circular SD was computed as follows: c.s.d. $=$ $(-2 \log (L))^{0.5}$, where $L$ is the mean resultant vector length of the unit vectors (Fisher, 1993). To compare different samples of angles, we used the nonparametric Mardia-Watson-Wheeler test (Fisher, 1993), and the parametric Watson-Williams $F$ test when at least one of the samples had $<10$ observations. These statistical tests were performed using the software Oriana 2.0 (Kovach Computing Services). Student's $t$ test and ANOVA were used to test for statistical differences between groups. Histograms of the escape latency were fit by a sum of Gaussian functions using the nonlinear fit function using the software Origin 8 (OriginLab), and the goodness of fit $R^{2}$ ranged from 0.838 to 0.909 . Exact binomial confidence intervals were calculated as described previously (Clopper and Pearson, 1934).

To describe the time course of the slow PSP, the sound-evoked response was low-pass filtered by a second-order digital Butterworth filter with a low-frequency cutoff at $60 \mathrm{~Hz}$. To identify, across experiments, the relationship between the low-pass EPSP amplitude, $\operatorname{LP}(t)$, and stimulus amplitude, we used an exponential function, $r(t)=A^{\star} e^{\left(\mathrm{LP}(t)^{*} \tau\right)}$, which was tested for goodness of fit and statistical significance by a linear regression analysis of the experimental versus predicted data with a criterion of $p<0.0001$. Using the mean $A$ and $\tau$ values from the model, we then calculated the inverse function for each stimulus condition.

To measure the intensity threshold at which response onset occurs for the action potentials, and the behavior, the corresponding stimulus waveform was truncated at the response onset. We then calculated the pressure (r.m.s.), in pascals, of the truncated waveform. The sound intensity (in watts per square meter) was calculated as the pressure (r.m.s. $)^{2} /$ impedance of the medium. The impedance of air was takes as $4.1 \times 10^{2}$ rayls and that of water as $1.4 \times 10^{6}$ rayls (Lombard et al., 1981). To calculate the peak SPL at response onset, we measured the instantaneous pressure (in pascals) of the corresponding stimulus by evaluating the stimulus amplitude envelope function $r(t)$. For each escape behavior, we estimated the location-specific sound intensity threshold, and peak
SPL threshold, by dividing the aquarium into 10 zones and recording the stimuli in each zone with a hydrophone. High-speed video recording of the escape was used to assign each escape to a zone. The adjusted EMG latency was then used to both truncate the corresponding locationspecific stimulus waveform and to evaluate its $r(t)$. Because we did not account for the depth of the fish, these measurements can only be taken as approximations.

To estimate the phase angle that evoked the fast EPSPs, we adjusted the measured phase angles to account for sensory processing time (i.e., the delay between hair cell transduction and the arrival of the fast EPSP in the $\mathrm{M}$-cell). This interval was estimated as ranging from a minimum of 1.4 ms, which is the established approximate latency of a PSP in the M-cell evoked by a $500 \mathrm{~Hz}$ sound pip in air with an intensity of $\geq 97 \mathrm{~dB}$ reference (re): $20 \mu \mathrm{Pa}$, to a maximum of $4.5 \mathrm{~ms}$, which is the approximate latency of the PSP evoked by a $500 \mathrm{~Hz}$ pip in air with an intensity of $67 \mathrm{~dB}$ re: 20 $\mu \mathrm{Pa}$ (Casagrand et al., 1999). We also subtracted $\sim 0.5 \mathrm{~ms}$ to account for the half-width of the fast EPSP. For example, $150 \mathrm{~Hz}$ corresponds to a cycle period of $T=6.66 \mathrm{~ms}$, a sensory processing time of $1.4 \mathrm{~ms}+0.5 \mathrm{~ms}$ then corresponds to $102.6^{\circ}$, and a sensory processing time of $4.5 \mathrm{~ms}+0.5$ $\mathrm{ms}$ then corresponds to $270^{\circ}$. The corresponding values ranged from $119.36-270^{\circ}=209.36^{\circ}$ to $119.36-102.6^{\circ}=16.76^{\circ}$ (Fig. $2 A$ ). To estimate the phase angle and sound intensity that evoked the M-spike in behaving fish we subtracted $1.5 \mathrm{~ms}$ from the EMG latency, to account for the conduction time in the $\mathrm{M}$-axon and the synaptic delay at the neuromuscular junction (Zottoli, 1977), and another $1.4 \mathrm{~ms}$, to account for auditory processing. In this estimate, we assumed the minimum sensory processing time because the sounds in water were two orders of magnitude more intense than the sounds in air and most escapes occurred after the sound pressure exceeded $97 \mathrm{~dB}$ re: $20 \mu \mathrm{Pa}$.

\section{Results}

\section{Phase analysis of the sound-evoked PSP in the M-cell}

Sound-evoked PSPs were recorded from the M-cell soma in air. The stimuli, ramped 150,200, and $250 \mathrm{~Hz}$ sound waves $50 \mathrm{~ms}$ in duration and similar in peak intensity and slope $(150,200,250 \mathrm{~Hz}$ intensity $=1.30,1.86,1.23 \mu \mathrm{W} / \mathrm{m}^{2}$; peak SPL dB $=70.85,73.04$, 71.64, re: $20 \mu \mathrm{Pa}$ ), evoked a compound PSP consisting of electrotonic fast EPSPs superimposed on a depolarizing envelope, the slow EPSP (Fig. $2 A$ ). The response was high-pass filtered and fit with a peak detection program (Fig. $2 B$ ). Next, the amplitude of each peak along with its phase angle, with respect to the sound wave, was plotted in polar coordinates (Fig. 2C). In 15 experiments, the phase angle distributions of the responses evoked by the 150, 200, and $250 \mathrm{~Hz}$ ramped sound waves were nonrandom in 6,10 , and 11 cases, respectively (modified Kuiper's $V$ test, $p<$ $0.05 ; \mathrm{df}=4-22$ ). Usually, the phase angles clustered around two diametrically opposed values, although this was less evident in the responses evoked by the $150 \mathrm{~Hz}$ stimulus. The typically more coherent cluster with the larger fast EPSP events, was designated the primary distribution, and the less coherent cluster composed of the smaller events, the secondary distribution. In accord with these assignments, the mean vector length, a measure of amplitude and coherence, of the fast EPSPs in the primary distribution exceeded that of the secondary distribution in all but 2 of the 15 experiments (paired Student's $t$ test, $p<0.01$ ).

The VSs for the primary distributions of fast EPSPs evoked by the 150, 200, and $250 \mathrm{~Hz}$ stimuli, calculated across subjects $(N)$ and sweeps $(n)$, were $0.745 \pm 0.10,0.816 \pm 0.07,0.814 \pm 0.09$ (mean $\pm \mathrm{SD}, N=15, n=4-10$ ), respectively, and were frequency dependent (ANOVA: $p=0.042 ; F=3.41$, df $=2$ ), The mean VSs for the secondary distributions evoked by the 150, 200, and $250 \mathrm{~Hz}$ stimuli were $0.718 \pm 0.10,0.753 \pm 0.09,0.780 \pm 0.11$ (Fig. $2 D$ ), and were not frequency dependent (ANOVA: $p=$ $0.234 ; F=1.50, \mathrm{df}=2)$. The corresponding mean phase angles of the primary distribution of fast EPSPs evoked by the 150,200, and $250 \mathrm{~Hz}$ ramped sound waves, calculated across subjects and 
sweeps, were $119.36 \pm 27.7^{\circ}, 186.48 \pm$ $20.6^{\circ}, 207.23 \pm 23.0^{\circ}$ (mean \pm c.s.d.; $N=$ $15, n=4-10)$, respectively, and were frequency dependent (Mardia-WatsonWheeler test, $p<0.01)$. The mean secondary phase angles were $298.22 \pm 34.4$, $4.70 \pm 23.3,20.91 \pm 25.5^{\circ}$, respectively, and were not frequency dependent (Mardia-Watson-Wheeler test, $p=0.115$ ) (Fig. 2D). When we adjusted the mean phase angles of the primary distributions to account for a range of sensory processing times ( 1.4 to $4.5 \mathrm{~ms}$ ) (see Materials and Methods), the corresponding values ranged from $\sim 214$ to $13^{\circ}, 193$ to $50^{\circ}$, and 105 to $35^{\circ}$, for the responses evoked by the 150,200 , and $250 \mathrm{~Hz}$ ramped sound waves, respectively. If the sensory processing time is minimal (i.e., $\sim 1.4-2.4 \mathrm{~ms}$ ), the fast EPSPs in the primary distributions are evoked by sound compression $\left(270-90^{\circ}\right)$, and hence those in the secondary distributions are evoked by rarefaction, whereas if the sensory processing time is longer, this relationship may be reversed.

Because the stimuli were ramped, we also asked whether there might be a correlation between the intensity of the sound wave and the phase angle of the fast EPSP. As the stimulus increased in intensity with time, the phase angle of the resulting fast EPSPs remained nearly constant, decreasing by only $\sim 30-40^{\circ}$ (Fig. $2 E$ ). We also observed that a louder $250 \mathrm{~Hz}$ ramped sound wave (intensity $=5.08 \mu \mathrm{W} / \mathrm{m}^{2}$; peak SPL $\mathrm{dB}=77.55$, re: $20 \mu \mathrm{Pa}$ ) evoked a response in which the mean phase angles of the primary and secondary distributions were the same as those evoked by the softer stimulus (Mardia-WatsonWheeler test, $p=0.671,0.358 ; N=15, n=$ $4-10)$. In light of this observation, it is unlikely that, in response to the ramped stimulus, sensory processing time is intensity dependent.

\section{The timing of C-starts evoked by ramped sound waves}

Because the ramped sound pressure waves in air evoked PSPs in the M-cell that encoded phase, we next sought to determine whether phase encoding would also be evident at the behavioral level underwater in response to sound stimuli that include pressure and particle motion components. EMGs that generate the C-start escape have been found to be simultaneous along the rostral-caudal axis in the region of the midbody (Jayne and Lauder, 1993) and thus provide submillisecond accuracy of the escape latency and an estimate of the timing of the M-spike. We quantified the onset of the escape behavior as the latency from stimulus onset to the onset of the EMG response. A total of 283 escapes in six fish were analyzed. Ramped sound
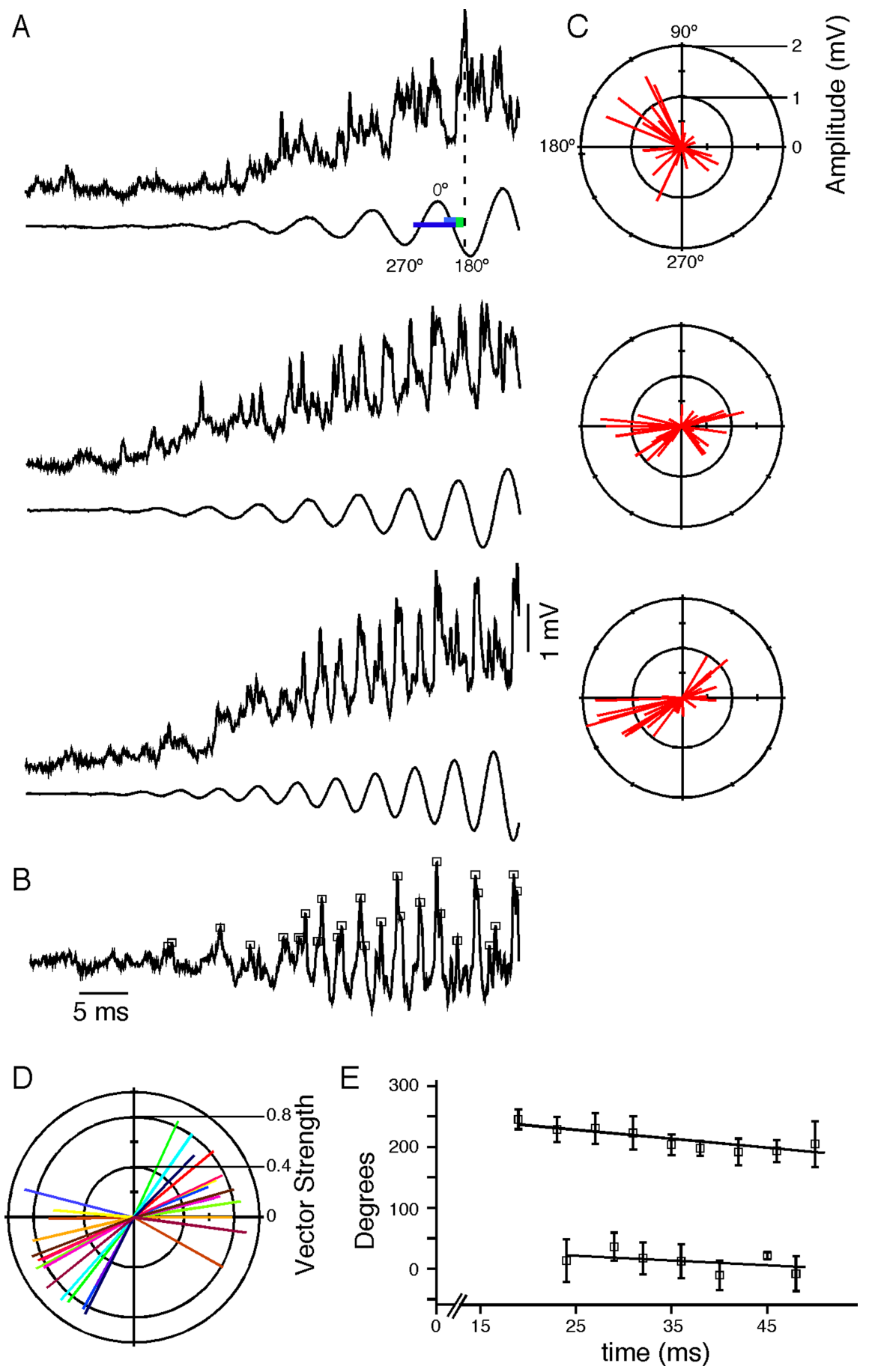

Figure 2. The sound-evoked fast EPSPs are phase locked. $A$, PSPs recorded from the M-cell soma evoked by $150 \mathrm{~Hz}$ (top), 200 $\mathrm{Hz}$ (middle), and $250 \mathrm{~Hz}$ (bottom) ramped sound waves. The vertical dashed line (top) indicates peak time of a fast EPSP. The green, light blue, and dark blue horizontal bars correspond to the estimated fast EPSP half-width, minimum, and maximum sensory processing times, respectively. $\boldsymbol{B}$, The high-pass filtered PSP evoked by the $250 \mathrm{~Hz}$ sound wave with peak fits (squares). $\boldsymbol{C}$, Polar plots of the phase angle and amplitude of the fast EPSP events evoked by the $150 \mathrm{~Hz}$ (top), $200 \mathrm{~Hz}$ (middle), and $250 \mathrm{~Hz}$ (bottom) ramped sound waves. $\boldsymbol{D}$, Summary plot ( $N=15$ experiments; color coded) of the calculated mean primary and secondary phase angle and vector strength of the fast EPSP events evoked by the $250 \mathrm{~Hz}$ sound wave. $\boldsymbol{E}$, A plot of the mean and SD ( $n=6$ sweeps; $1-2$ ms bins) of the phase angle of each fast EPSP peak evoked by the $250 \mathrm{~Hz}$ sound wave versus time from a single experiment. Linear fits were performed on the individual data points in the primary and secondary distribution.

waves $50 \mathrm{~ms}$ in duration with frequencies of $150 \mathrm{~Hz}(N=4 ; n=$ 108), $200 \mathrm{~Hz}(N=4 ; n=81)$, and $250 \mathrm{~Hz}(N=4 ; n=94)$ evoked EMG activity that appeared similar in waveform from trial to trial in individual fish executing C-starts to the same side (Fig. $3 A$ ). Across fish, the escape probability in response to the 150,200, and 


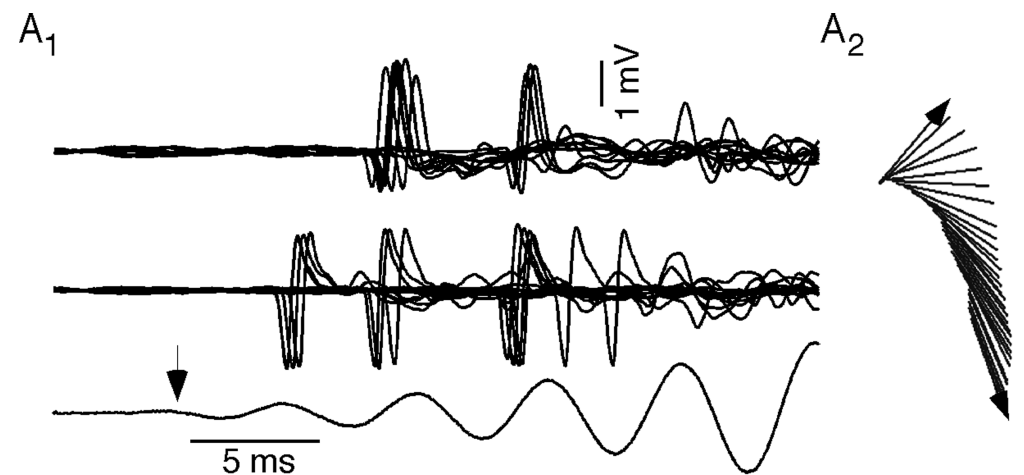

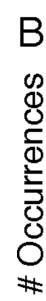
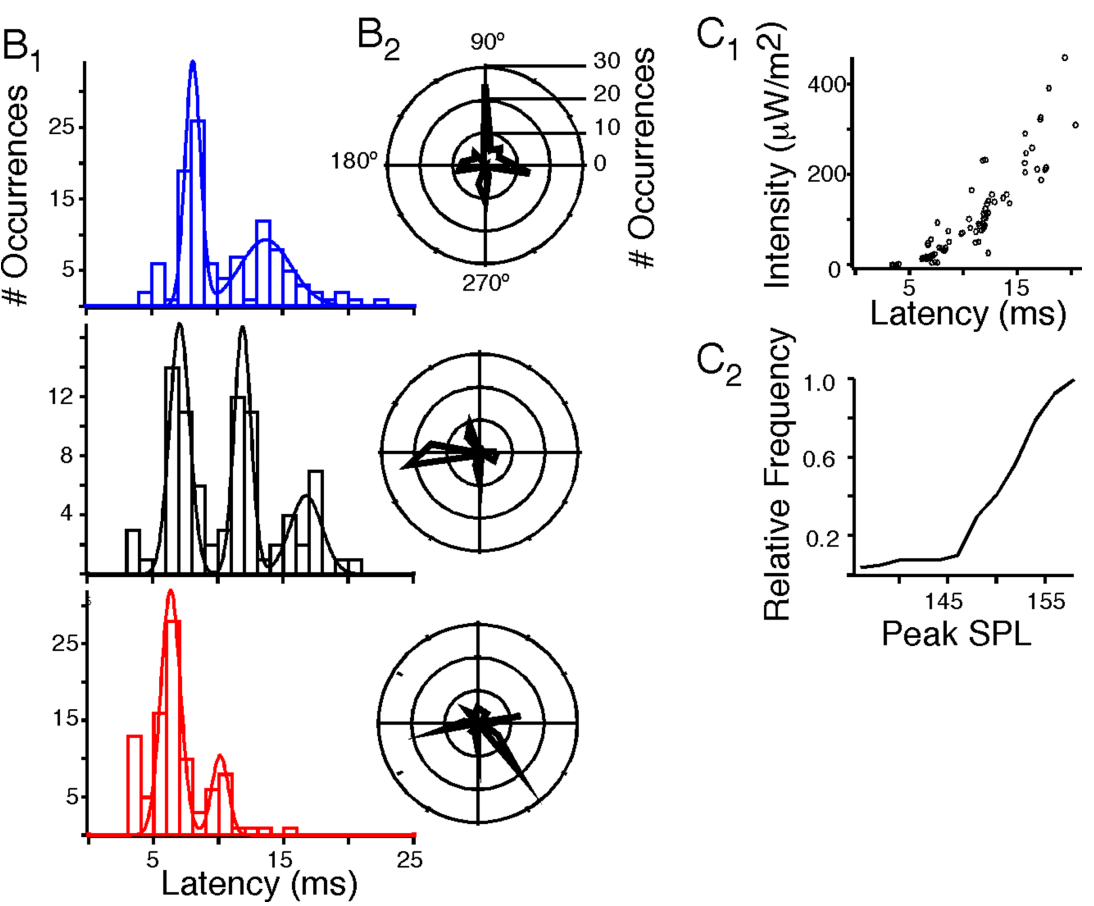

$\mathrm{C}_{2}$

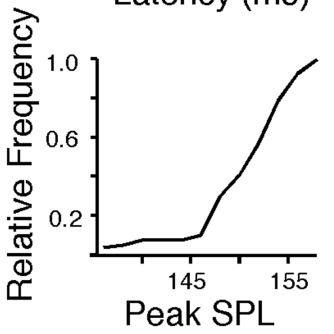

Figure 3. The timing of the C-start behavior evoked by ramped sound waves is phase locked. $A$, EMGs recorded from the right $n=14$ (top), and left, $n=13$ (middle), trunk muscle correlated with C-starts to the right and left, respectively, evoked by the 200 $\mathrm{Hz}$ ramped sound wave (below) in a single fish (A1). A single trial is correlated with a single biphasic EMG event; the arrow indicates stimulus onset. Movement, which begins $\sim 7 \mathrm{~ms}$ after the EMG, is shown as a composite plot of the fish's heading at 5 ms intervals (A2). $\boldsymbol{B}$, EMG onset is phase locked to the sound wave. The histogram of latency to EMG onset for pooled escapes elicited by the 150 (blue; $N=4$ fish, $n=108$ trials), $200 \mathrm{~Hz}$ (black; $N=4, n=81$ ), and $250 \mathrm{~Hz}$ (red; $N=4, n=94$ ) sound waves, fit by a multipeak sum of Gaussian functions (B1). Polar histogram of the phase angle of EMG onset for escapes evoked by the 150 (top), 200 (middle), and $250 \mathrm{~Hz}$ (bottom) sound waves, respectively (B2). Note that the distributions are nonuniform and are characterized by a single predominant peak (B2). C, The corresponding estimated location specific sound level threshold of the C-start escape is variable, as evident by the intensity threshold as a function of EMG latency (C1) and the cumulative relative frequency of the threshold peak SPL in decibels re: $1 \mu \mathrm{Pa}$ (C2).

$250 \mathrm{~Hz}$ stimuli was $0.552 \pm 0.15,0.387 \pm 0.08,0.402 \pm 0.11$, respectively. The timing of EMG onset did not change over the course of any of the six experiments, but in four of six the cumulative escape probability decreased by $\sim 0.025$ to 0.3 (supplemental Fig. S1, available at www.jneurosci.org as supplemental material), possibly because of auditory conditioning (Oda et al., 1998), or habituation.

With a couple of exceptions, all the EMGs occurred at latencies $<22 \mathrm{~ms}$ after stimulus onset (Fig. $3 B$ ). Both the superimposed sweeps of individual EMGs evoked by the $200 \mathrm{~Hz}$ sound wave, from a single experiment (Fig. 3A), and a pooled histogram of the latency to EMG onset $(N=4 ; n=81)$ (Fig. $\left.3 B_{1}\right)$, demonstrate that the EMG latencies are distributed in two to four clusters and that the interval between the clusters approximates the stimulus period. Also, the latency of the initial two clusters appeared to be correlated with stimulus frequency (Fig. 3B).

We measured the phase angle of EMG onset for each trial and constructed polar histograms of the distributions (Fig. $3 B_{2}$ ). The distribution of phase angles was nonuniform by Rayleigh's test $(150,200,250$ Hz: $Z=4.84,16.45,4.17 ; p<0.05 ; n=$ $108,81,94)$ and frequency dependent (Mardia-Watson-Wheeler test, $p<0.01$ ) further indicating that the timing of the EMG, and of the M-spike, is phase locked. The mean phase angles ( \pm c.s.d.) of EMG onset for escapes evoked by 150, 200, and $250 \mathrm{~Hz}$ ramped sound waves were $70.78 \pm$ $66.51,194.17 \pm 47.65$, and $326.56 \pm$ $66.00^{\circ}$, respectively. To calculate the phase angle at which the M-spike is elicited, and whether it is evoked by sound compression or rarefaction, we adjusted these phase angles to account for sensorimotor processing (see Materials and Methods). Accordingly, the mean adjusted phase angles at which the $\mathrm{M}$-cell reached threshold were 355,92 , and $186^{\circ}$, which, when further adjusted for sensory processing time, corresponded to sound wave phase angles of 280,349 , and $56^{\circ}$ for the 150,200 , and $250 \mathrm{~Hz}$ stimuli, respectively. These estimates differ from those obtained for fast EPSPs evoked in air. Values between 280 and $56^{\circ}$ indicate that underwater the phase-locked M-spike is primarily elicited by the increasing and decreasing phases of sound compression $\left(270-90^{\circ}\right)$.

To explore whether the behavior is elicited when the stimulus reaches a specific intensity, as opposed to a specific phase, we calculated the estimated location specific intensity threshold for each C-start escape in the experimental tank. The calculated intensity thresholds were diverse (Fig. 3C), ranging over two orders of magnitude, indicating that the escape does not occur as a result of the sound pressure intensity reaching a set threshold.

We also specifically asked whether responses evoked by ramped sound waves were directed away from the sound source (i.e., directional). For responses in which directionality could be clearly assessed, the number of correct responses (i.e., away from the sound source) was $72.72 \%$ for the $150 \mathrm{~Hz}$ ramped sinusoid $(n=45), 75.0 \%$ at $200 \mathrm{~Hz}(n=44)$, and $79.4 \%$ for the $250 \mathrm{~Hz}$ ramped sinusoid $(n=$ 73 ), and significantly greater than chance (binomial confidence interval, $p<0.05$ ). No clear relationship between the latency distribution, or the phase angle, of the escape and the directionality of the response was clearly evident in the dataset.

\section{Phase analysis of sound-evoked activity in feedforward inhibitory interneurons}

Having established that phase encoding is evident both in the sound-evoked electrotonic excitation of the M-cell and in the 
timing of the directional C-start behavior, we next asked whether activity in feedforward neurons, which inhibit the M-cell electrically and chemically, would also encode phase. These inhibitory neurons can be identified by their characteristic electrophysiological signature, an intracellular hyperpolarizing transient called a PHP that is simultaneous with the antidromic M-spike (Korn and Faber, 1975). The PHP is a sign of a field effect mediated by the action currents of the M-cell. A field effect is distinguished and quantified by computing the difference between an intracellular response $\left(V_{\mathrm{i}}\right)$ and the corresponding extracellular field recorded just outside the site of the intracellular recording $\left(V_{\mathrm{e}}\right)$. The $\mathrm{PHP}$ is larger than the corresponding extracellular field, and thus the net transmembrane potential change $\left(V_{\mathrm{m}}\right)$ is a hyperpolarization (Fig. 4A). The "PHP" neurons selected in this study had a transmembrane PHP amplitude of $-1.13 \pm 0.8$ $\mathrm{mV}(N=10)$, consistent with previous reports (Zottoli and Faber, 1980).

In contrast to the $\mathrm{M}$-cell, the ramped sound wave stimuli mostly elicited suprathreshold responses in PHP neurons (Fig. $4 B$ ). The sound intensity at which an action potential was first evoked varied across the individual neurons (Table 1), and 2 of the 10 responded during reverberation after stimulus termination. The action potentials evoked by the ramped sound waves appeared to be phase locked in all eight of the PHP neurons that did reach threshold, and some PHP neurons responded at two diametrically opposed phase angles (Fig. 4C). To calculate the mean phase angle, SD, and VS of the action potentials in the PHP neurons, we pooled the calculated corresponding phase angles from single sweeps because many of the PHP neurons, especially those with high thresholds, responded to the ramped sound waves with only 1-3 action potentials and often skipped cycles. The combined distribution of the calculated phase angles of the action potentials was circularly nonrandom in all but one cell responding to the $200 \mathrm{~Hz}$ stimulus and two cells responding to the $250 \mathrm{~Hz}$ stimulus ( $V$ test, $p<0.05$; df $=6-24$ ), and the average VS of the total or primary distribution of action potentials evoked by 150,200 , and $250 \mathrm{~Hz}$ stimuli was $0.919 \pm 0.12$, $0.900 \pm 0.09,0.900 \pm 0.09$ (Fig. $4 C)(N=8)$, respectively. The mean phase angle of synchronization was similar across some but not all PHP cells (Table 1, Fig. 4D), and in six of seven, the distribution of phase angles was frequency dependent (WatsonWilliams $F$ test, $p<0.01$; $\mathrm{df}=6-24)$. In one-half of the experiments, we clearly observed subthreshold PSPs in PHP neurons that also appeared to be phase locked (Fig. $4 E$ ). The short halfwidth of these synaptic potentials $(\sim 0.5 \mathrm{~ms})$ indicates that they

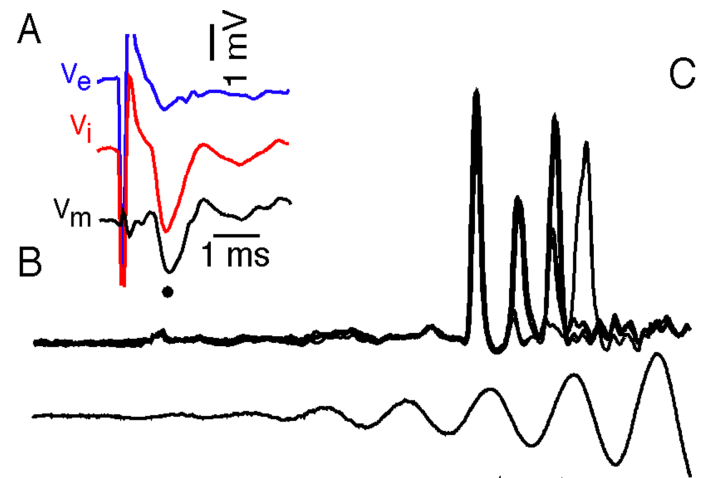

C
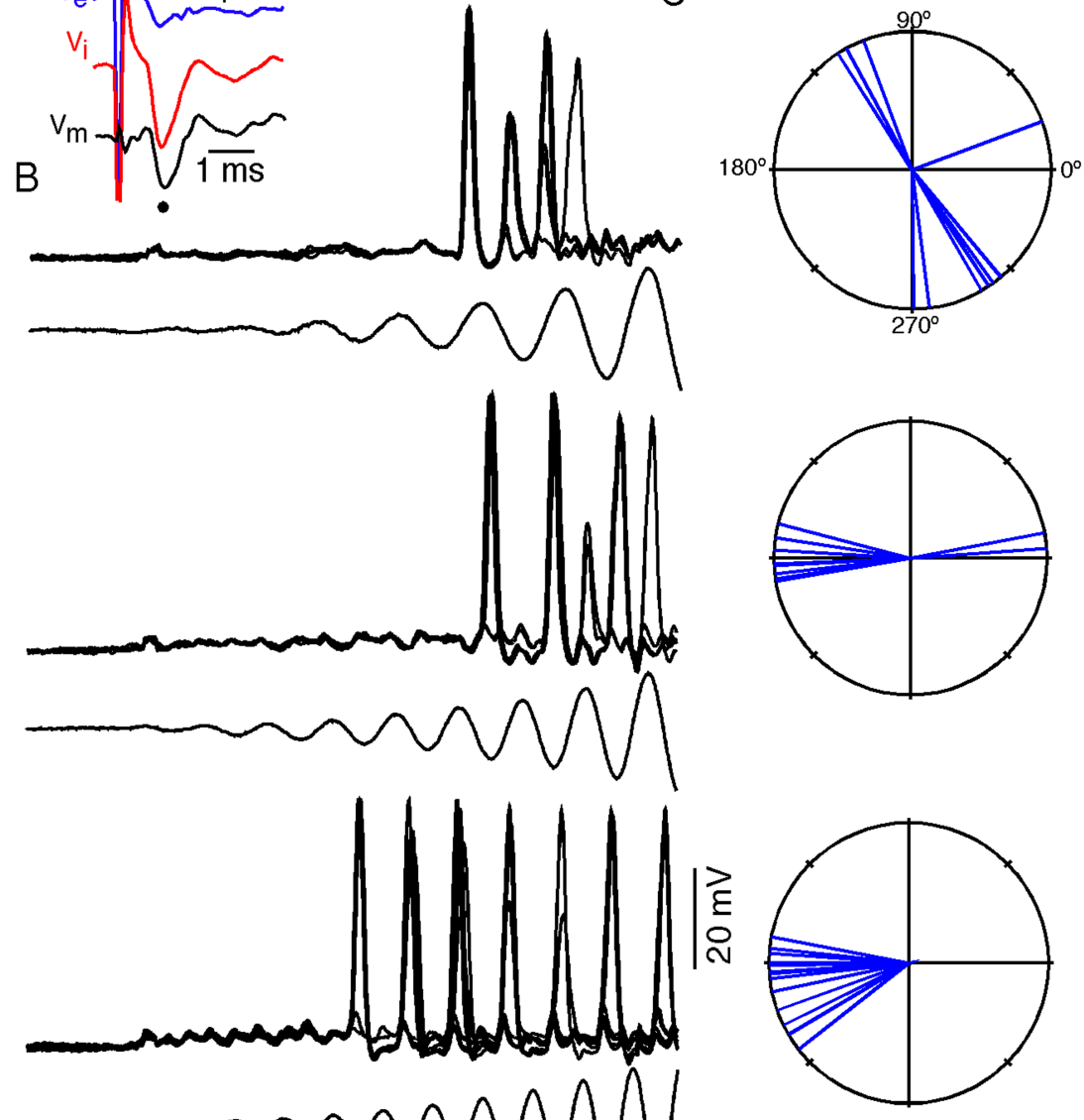

Figure 4. Action potentials in (PHP) inhibitory interneuron axons are phase locked. A, PHP evoked by antidromic stimulation of the M-axon and used to identify a PHP neuron. The negative-going M-spike (black dot) is smaller extracellularly by the soma $\left(V_{\mathrm{e}}\right)$ than intracellularly $\left(V_{\mathrm{i}}\right)$, so that the net transmembrane potential change $\left(V_{\mathrm{m}}=V_{\mathrm{i}}-V_{\mathrm{e}}\right)$ (dashed trace) is a hyperpolarization. $\boldsymbol{B}$, Superimposed multiple sweeps ( $n=5-7$ ) of action potentials evoked in a PHP axon by $150 \mathrm{~Hz}$ (top), $200 \mathrm{~Hz}$ (middle), and $250 \mathrm{~Hz}$ (bottom) ramped sound waves. The bottom sweep in each pair is the sound stimulus. C, Polar plots of the phase angle of the pooled $(n=5-7)$ action potentials evoked by the three stimuli. $D$, Summary plot ( $N=8$ cells; colors) of the mean phase angle(s) and vector strength(s) of the action potentials evoked by the $250 \mathrm{~Hz}$ ramped sound wave. $\boldsymbol{E}$, Subthreshold PSPs evoked by the 250 $\mathrm{Hz}$ sound wave in a PHP neuron (E1) and polar plot of their phase angles (E2).

are electrotonic in origin, as has been previously suggested (Zottoli and Faber, 1980; Triller and Korn, 1981).

\section{Characterization of sound-evoked electrical inhibition}

Having determined that the ramped sound waves evoke phaselocked action potentials in individual PHP neurons, we next looked at the resulting electrical inhibition of the M-cell. The action currents in the PHP axons passively flow out at the axon terminal producing a current source in the axon cap and a corresponding extracellular positivity, referred to as the EHP (Furukawa and Furshpan, 1963), that hyperpolarizes the M-cell axon 
Table 1. Response properties of individual PHP neurons

\begin{tabular}{|c|c|c|c|c|}
\hline \multirow[b]{2}{*}{ Neuron } & \multirow[b]{2}{*}{ Mean intensity at onset $\left(\mu \mathrm{W} / \mathrm{m}^{2}\right)$} & \multicolumn{3}{|c|}{ Fundamental angle $\left({ }^{\circ}\right)$} \\
\hline & & $250 \mathrm{~Hz}$ & $200 \mathrm{~Hz}$ & $150 \mathrm{~Hz}$ \\
\hline 1 & $0.336 \pm 0.102$ & $180.39 \pm 13.0$ & $183.47 \pm 4.0$ & $117.215^{a} \pm 3.3$ \\
\hline $2^{b}$ & $0.008 \pm 0.001$ & $204.68^{a} \pm 27.2$ & $174.22^{a} \pm 13.1$ & $173.62^{a} \pm 32.8$ \\
\hline 3 & $3.842 \pm 0.617$ & $43.97 \pm 4.5$ & & \\
\hline 4 & $0.085 \pm 0.016$ & $48.61^{a} \pm 19.51$ & $338.08^{a} \pm 6.3$ & $286.94^{a} \pm 7.9$ \\
\hline 5 & $1.741 \pm 1.090$ & $317.73 \pm 8.0$ & $287.21^{a} \pm 26.9$ & $89.75^{a} \pm 6.3$ \\
\hline 6 & $1.134 \pm 1.145$ & $18.89^{a} \pm 2.11$ & $327.05^{a} \pm 21.7$ & $272.71^{a} \pm 22.8$ \\
\hline 7 & $0.077 \pm 0.017$ & $217.21 \pm 29.3$ & $178.27^{a} \pm 29.2$ & $114.57 \pm 11.9$ \\
\hline 8 & $2.606 \pm 1.925$ & $277.57^{a} \pm 17.1$ & $293.02^{a} \pm 26.6$ & $284.88^{a} \pm 1.0$ \\
\hline
\end{tabular}

Mean threshold at onset was calculated for responses evoked by the $250 \mathrm{~Hz}$ stimulus.

${ }^{a}$ Neurons that exhibited responses at both primary and secondary phase angles.

${ }^{b}$ The neuron in which the distribution of phase angles was not frequency dependent (Watson-Williams $F$ test, $p>0.05$ ).
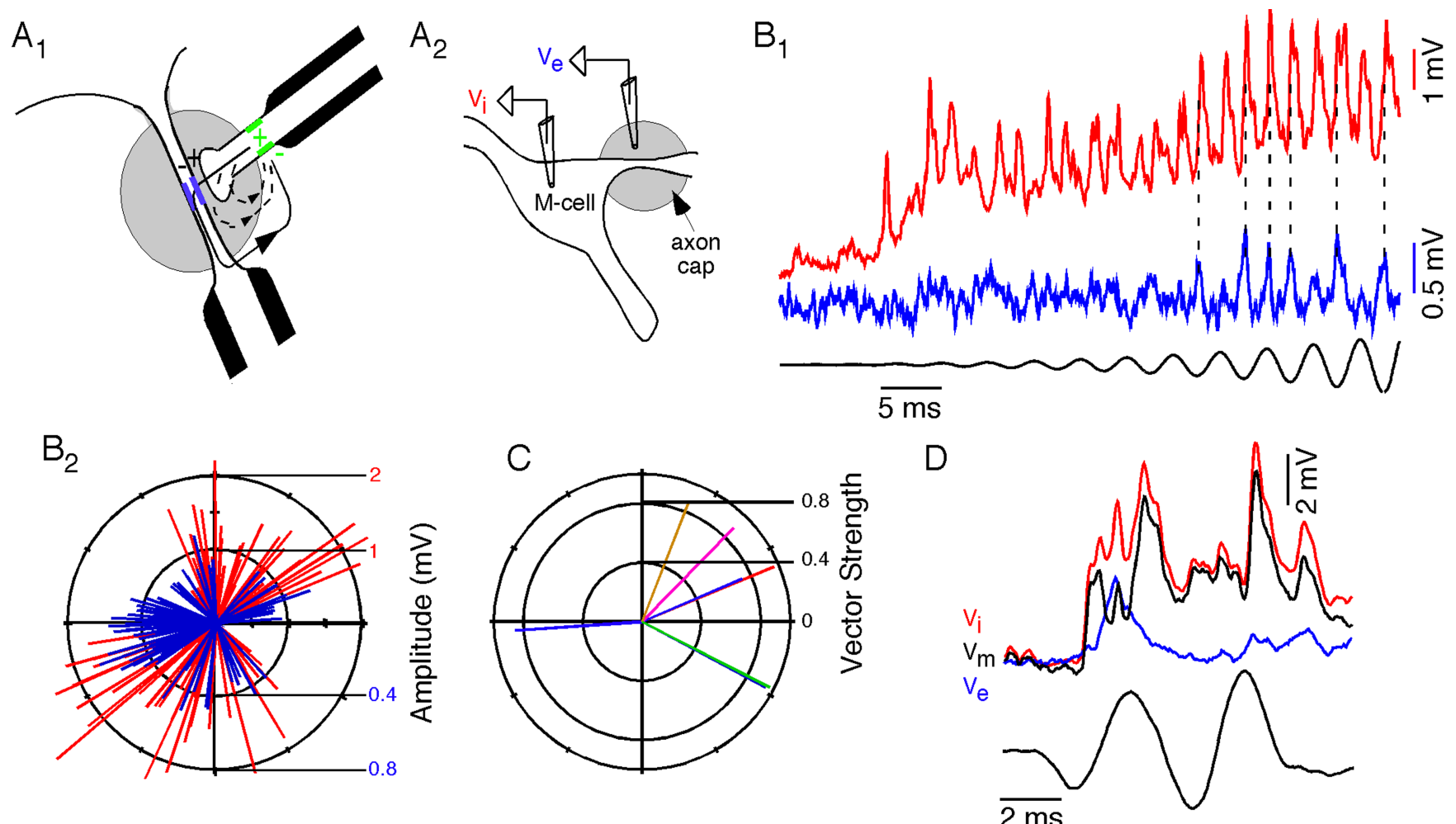

Figure 5. Electrical inhibition is phase locked and is coincident with the fast EPSPs. $\boldsymbol{A}$, The mechanism of electrical inhibition and recording arrangement. $\boldsymbol{A} \mathbf{1}$, Inward currents generated at the excitable heminode (green) or last node of Ranvier of a PHP axon flow passively out at the unmyelinated portions in the cap and inward across the membrane of the axon hillock (blue) of the M-cell. The axon cap, a region of high extracellular resistivity (gray), reduces extracellular currents returning to the heminode or last node of Ranvier within the cap (dashed). The inhibiting field, the EHP, is positive in the cap. A2, Sound-evoked PSPs and EHPs are recorded intracellularly $\left(V_{i}\right.$; red) and extracellularly $\left(V_{e} ;\right.$ blue $)$ from the M-cell soma and axon cap, respectively. $\boldsymbol{B}$, A single trace of the PSP (red) and the EHPs (blue) evoked by the $250 \mathrm{~Hz}$ sound wave. The vertical dashed lines indicate coincidence (B1). Superimposed polar plots ( $n=7 \mathrm{sweeps}$ ) of the phase angle of the EHPs (blue) and fast EPSPs (red) (B2). C, Summary plot ( $N=6$ experiments; colors) of the mean phase angle(s) and vector strength(s) of the EHPs evoked by the $250 \mathrm{~Hz}$ ramped sound wave. $\boldsymbol{D}$, The pip evoked response recorded intracellularly (red; $V_{\mathrm{i}}$ ) and extracellularly (blue; $V_{\mathrm{e}}$ ) and the transmembrane potential (black), calculated as follows: $V_{\mathrm{m}}=V_{\mathrm{i}}-V_{\mathrm{e}}$.

hillock (Fig. $5 A_{1}$ ). Some of the action currents are channeled intracellularly because of the relatively high electrical resistance of the axon cap. Consequently, the timing and magnitude of the EHP reflects the population activity of the PHP neurons, with a single action potential in a PHP neuron generating an EHP of $\sim 200-400 \mu \mathrm{V}$ (Korn and Faber, 1975).

To determine the timing and strength of electrical inhibition evoked by the ramped sound waves, electrodes were positioned in the M-cell soma and the axon cap to record the PSP $\left(V_{\mathrm{i}}\right)$ and EHP $\left(V_{\mathrm{e}}\right)$, respectively (Fig. $5 A_{2}$ ). Both $V_{\mathrm{i}}$ and $V_{\mathrm{e}}$ appeared to be phase locked and to coincide (Fig. $5 B$ ), but the electrical inhibition was typically weak because the transmembrane potential $\left(V_{\mathrm{m}}\right)$, calculated as $V_{\mathrm{m}}=V_{\mathrm{i}}-V_{\mathrm{e}}$, deviated little from $V_{\mathrm{i}}$ except for several of the later cycles of the ramp stimulus. The EHPs evoked by the 250 $\mathrm{Hz}$ ramped sound wave were distinguishable in only 6 of 15 experiments (Fig. 5C), and the 150 and $200 \mathrm{~Hz}$ stimuli failed to evoke clear EHPs in almost all the experiments, indicating that these stimuli either fail to activate a sizable population of PHP neurons, or that action potentials in the PHP neurons are phase locked to different angles, and therefore the population, or summated, EHPs are relatively small because their components are asynchronous. However, in five of the six experiments in which EHPs were elicited by the $250 \mathrm{~Hz}$ stimulus, the calculated phase angles of the pooled EHPs were circularly nonrandom ( $V$ test, $p<0.05 ; n=4-10$; mean $\mathrm{df}=21-52)$, indicating that the electrical inhibition was phase locked. 
We also asked whether a louder and more abrupt sound would evoke stronger electrical inhibition by synchronizing firing in a larger population of PHP neurons. The pip stimulus (intensity, $11.8 \mu \mathrm{W} / \mathrm{m}^{2}$; peak SPL dB $=77.0$ re: $20 \mu \mathrm{Pa}$ ) consistently evoked a response in which this was clearly the case (Fig. $5 D$ ), indicating that sound-evoked electrical inhibition can strongly influence the $\mathrm{M}$-cell transmembrane potential (Weiss et al., 2008).

\section{Characterization of sound-evoked glycinergic inhibition}

PHP neurons also inhibit the M-cell chemically by releasing glycine at synapses located on the M-cell soma and proximal dendrite (Korn and Faber, 1976). To characterize the sound-evoked glycinergic inhibition, we compared the sound-evoked PSPs recorded from the M-cell before and after strychnine was iontophoresed by a second electrode positioned near the border of the M-cell axon cap. We confirmed that strychnine was effective by measuring the magnitude of the glycinergic collateral IPSP in the M-cell soma, which is evoked by antidromic M-axon stimulation (Faber and Korn, 1982). After strychnine iontophoresis, the average reduction in the collateral inhibitory conductance was $30.47 \pm 6.75 \%$ (Fig. $6 A)(N=8)$. Strychnine did not affect the input conductance of the $\mathrm{M}$-cell because the amplitude of the control antidromic spike remained constant (Student's $t$ test, $p>0.05$ ).

Comparisons of the ramped sound wave-evoked PSPs before and after strychnine iontophoresis show that strychnine did not affect the timing of the fast EPSP events, but that it did increase the amplitude of the slow PSP (Fig. 6B). This was confirmed across experiments by comparing the mean phase angles, and VSs of the fast EPSPs in the primary and secondary distribution, calculated across individual sweeps $(n=4-10)$, before and after strychnine iontophoresis. For the responses evoked by the 150, 200, and $250 \mathrm{~Hz}$ ramped sound waves, these values were unchanged $(N=8$; paired Student's $t$ test, $p>0.05$; Watson-Williams $F$ test, $p>0.05$ ) (Fig. 6C). However, after strychnine iontophoresis, the mean integral of the slow (i.e., low-pass filtered) PSP ( $\Sigma$ LP), calculated across sweeps $(n=4-10)$, increased (Fig. $5 C$ ) (Student's paired $t$ test, $p<0.05 ; N=8$ ) for all three frequencies tested (Fig. 6D). On average, the strychnine-induced increase in the low-pass filtered PSP occurred around response onset and remained constant, or increased slightly, as stimulus intensity increased (Fig. 6E); however, the responses evoked by the 150,200 , and $250 \mathrm{~Hz}$ stimuli differed with respect to the sound intensity dependence of the inhibitory time course (supplemental Fig. S2, available at www.jneurosci.org as supplemental material).

\section{Discussion}

We showed that phase encoding is an integrative feature of auditory processing in the $\mathrm{M}$-cell system, providing indirect evidence supporting the phase model for left-right underwater sound source discrimination. Phase coding is expressed in the (1) electrotonic excitation of both the M-cell and PHP inhibitory interneurons, (2) PHP neuron-mediated electrical inhibition of the M-cell, and (3) M-spike timing in free-swimming fish. These findings offer clues to biophysical mechanisms underlying decision making in the M-cell system.

\section{Electrical transmission mediates phase encoding}

Kozloski and Crawford (1998) speculated that electrical synapses mediate phase encoding in fish auditory brainstem circuits. The present and previous data (Szabo et al., 2006) support this hy-
A

Control

Strychnine
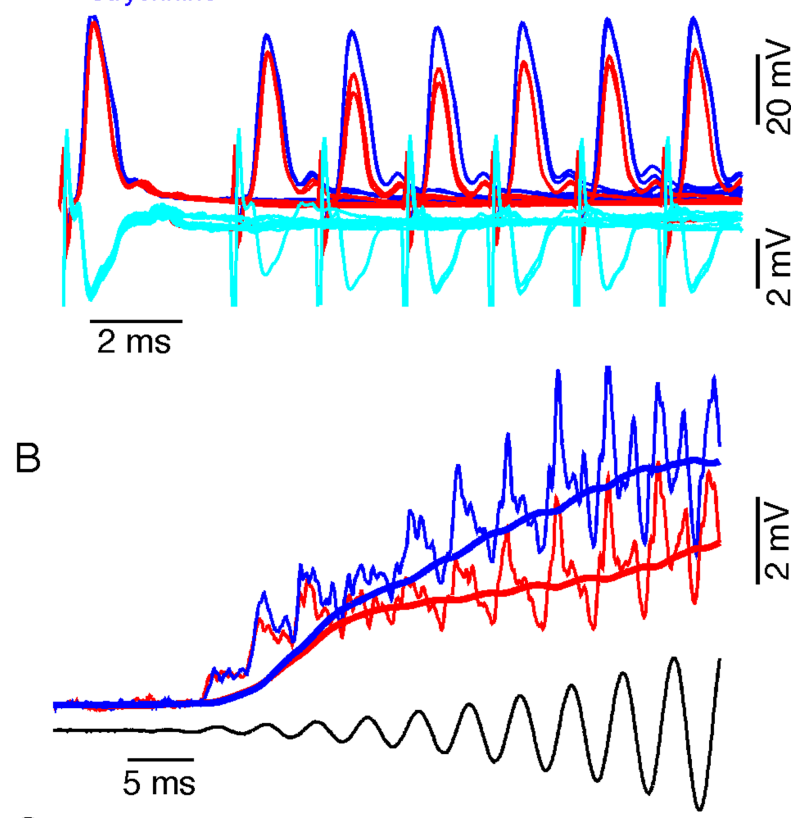

C
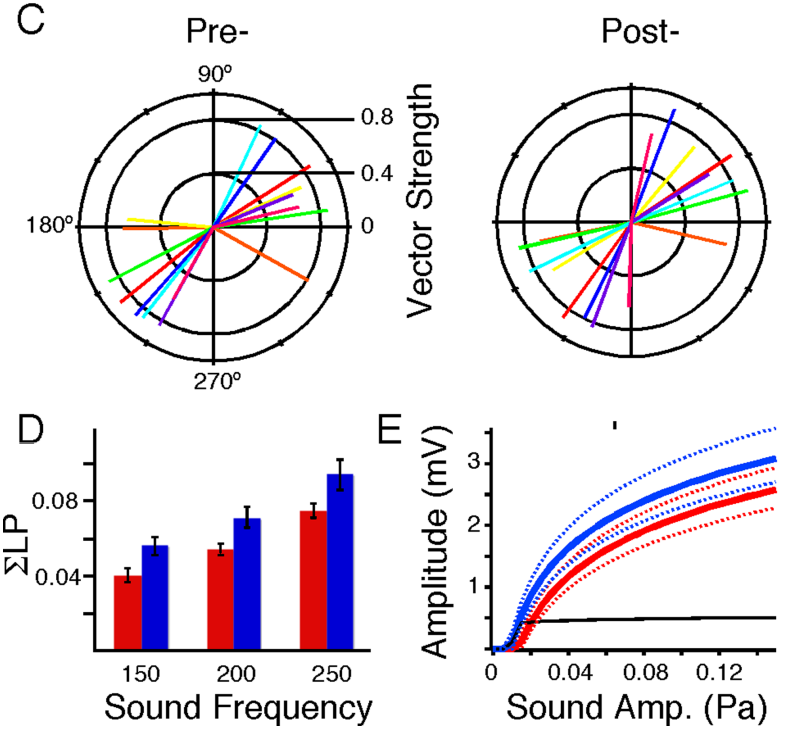

Figure 6. Sound-evoked chemical inhibition modulates the slow EPSP but does not influence the timing of fast EPSPs. $\boldsymbol{A}$, Collateral inhibition, as demonstrated by the shunt of a second of a pair of M-cell antidromic spikes. Superimposed sweeps at different intervals, obtained before (red) and after (blue) strychnine iontophoresis near the border of the axon cap, which reduces the inhibition. Below is the extracellular recording (cyan) obtained with the strychnine electrode. $\boldsymbol{B}$, Average PSP ( $n=5$ ) evoked in the M-cell soma by the $250 \mathrm{~Hz}$ ramped sound wave, and its low-pass filtered representation (solid line), recorded before (red) and after (blue) strychnine iontophoresis. C, Summary plots $(N=8)$ of the primary and secondary mean phase angles and vector strengths of the fast EPSPs prestrychnine and poststrychnine iontophoresis. $D$, Bar plots of the integral of the mean low-pass filtered PSP $(N=8 ; n=4-10)$ for the responses evoked by the 150,200, and $250 \mathrm{~Hz}$ ramped sound waves before (red) and after strychnine iontophoresis (blue). Error bars indicate SEM. $\boldsymbol{E}$, The mean $(N=8 ; n=4-10)$ logarithm fit of the low-pass filtered PSP amplitude $(N=8)$ as a function of the $250 \mathrm{~Hz}$ ramped sound wave amplitude, before (red) and after (blue) strychnine iontophoresis, and the difference (black); the dotted lines indicate $S E(N=8 ; n=4-10)$.

pothesis for the excitatory and inhibitory branches of the M-cell circuit (Figs. 2A, 4E). Because phase encoding is mediated by specialized AMPA receptors in birds and mammals (Carr et al., 2001), perhaps an evolutionary theme in the vertebrate auditory 
brainstem is a transition from electrical to chemical synapses in transmitting phase-locked information. Electrical synapses also mediate phase encoding in the neural systems underlying electroreception in weakly electric fish (Carr and Friedman, 1999). Its accuracy permits temporal comparisons between the zero crossings of the electrical signals at different parts of the body surface in the small cells of the torus semicircularis, thought to be important in the jamming avoidance reflex (Heiligenberg and Rose, 1985; Carr et al., 1986a,b). By analogy, phase comparisons in the $\mathrm{M}$-cell circuit may function to resolve the $180^{\circ}$ ambiguity problem. They could occur in either the M-cell lateral dendrite or the PHP cells when phase-locked electrotonic potentials, encoding either pressure or particle motion, coincide and summate. Alternatively, a phase comparison may occur at the M-axon hillock. In support of the latter, we observed that the ramped sound pressure waves evoked coincident phase-locked fast EPSPs and EHPs (Fig. $5 B)$. However, the strength of electrical inhibition evoked by ramped stimuli in air was weak and it is therefore questionable whether it regulates the threshold of the C-start. In contrast, electrical inhibition elicited by the pip stimulus was sufficiently strong (Fig. 5D), and appropriately timed (Weiss et al., 2008), to influence behavioral threshold. Regardless, sound-evoked electrical inhibition is ideally suited for phase encoding because neurotransmission is achieved with little synaptic delay and the inhibitory potential is not slowed by ligand-gated receptor kinetics. Underwater recordings should clarify whether the information is encoded by electrical inhibition and whether it is sufficiently strong to regulate C-start threshold.

\section{Auditory processing properties in the periphery}

Phase encoding in the M-cell system depends critically on the auditory processing properties of statoacoustic endorgans and afferents. The M-cell lateral dendrite is electrically coupled to 100 "S1" type saccular afferents (Bartelmez, 1915; Furukawa and Ishii, 1967), and a single action potential in one fiber generates a coupling potential (i.e., electrical EPSP) of $\sim 140 \mu \mathrm{V}$ in the soma (Lin and Faber, 1988). Because fast EPSPs were phase locked to the sound pressure wave (Fig. 2C), action potentials in individual $\mathrm{S} 1$ afferents must be locked to common angles. Also, because the phase angles of fast EPSPs were frequency dependent and intensity independent (Fig. 2E), these properties must also pertain for the action potentials of the saccular afferents. In mammalian and avian auditory afferents, the phase angle of synchronization is also frequency dependent, because the signal is subject to a delay that is partially independent of frequency. Also, when the stimulus frequency matches the best frequency of a fiber, the phase angle of synchronization is intensity independent (Anderson et al., 1971; Viete et al., 1997). In toadfish saccular afferents, however, the phase angles of responses elicited by sinusoidal displacement stimuli are intensity dependent (Fay and EddsWalton, 1997). Possibly sound pressure and acceleration produce different motion across the saccular cilia.

The phase-encoding property of PHP neurons (Fig. 4C) is probably dictated by that of the saccular afferents to which they are electrotonically coupled (Marti et al., 2008). A common afferent population likely innervates the M-cell and the PHP neurons because the mean phase angles of EHPs and fast EPSPs are comparable (Fig. 5B). Their coincidence also implies that, despite the extra electrical synapse, the conduction times for the excitatory and inhibitory pathways are similar (Carr and Konishi, 1988; 1990), as when the posterior VIIIth nerve is electrically stimulated (Faber et al., 1991) or responses are evoked by abrupt pip stimuli (Fig. 5D). Another similarity between these two responses was the bimodal distribution of phase angles (compare Figs. 2C, 4). This may be because activated hair cells in the ventral and dorsal region of the sacculus are of opposite polarities (Hama, 1969; Popper, 1977) and respond to sound compression and rarefaction, respectively (Furukawa and Ishii, 1967).

\section{Phase and intensity encoding and the timing of the C-start}

One indication that phase-locked activity plays an important functional role is that the timing of the C-start in freely swimming fish was also phase locked (Fig. $2 B$ ). The high degree of temporal precision of this sensorimotor integration process is comparable with that of the jamming avoiding reflex (Watanabe and Takeda, 1963). Presumably this is because a suprathreshold phase-locked EPSP, triggers the M-spike. However, the estimated mean phase angle of the M-spike did not correspond to that of fast EPSPs evoked in air. This inconsistency may reflect differences in the phase angle of synchronization in auditory afferents underwater as opposed to in air, or alternatively the influence of other sensory inputs (Eaton and Popper, 1995). However, our calculations suggest that sound compression elicited not only the $\mathrm{M}$-spike in most of the escape trials but also the larger and more coherent fast EPSPs in air, assuming the sensory processing time to be minimal. Notably, two previous behavioral studies, using different stimuli, also concluded the M-cell responds preferentially to sound compression (Canfield and Rose, 1996; Karlsen et al., 2004). Another timing-related question is whether higher frequency stimuli would also elicit phase locked M-spikes. Although ramped sound waves in air with frequencies up to $800 \mathrm{~Hz}$ elicit phase-locked fast EPSPs, the most robust M-cell responses are elicited by frequencies between 250 and $400 \mathrm{~Hz}$ (Weiss et al., 2005).

The relationship between the encoding of sound intensity and the threshold and probability of the C-start appears more complex. Intensity is encoded in the amplitudes of the fast and slow EPSPs in the M-cell (Szabo et al., 2006), and our results indicate the intensity encoding properties of the slow EPSP are regulated by feedforward glycinergic inhibition (Fig. 6). This inhibition is presumably functionally important (Oda et al., 1998), because reducing inhibitory tone in Medaka with strychnine increased the probability of evoking a C-start (Carlson et al., 1998). Feedforward supraspinal glycinergic inhibition likely also regulates threshold in the startle response of higher vertebrates because humans affected by the hereditary disease hyperekplexia reflexively startle to mild stimuli (Bakker et al., 2006).

We observed escapes in response to sound pressure intensities encompassing two orders of magnitude (Fig. 2C). It is worthwhile to consider that stochastic properties of synaptic transmission (Furukawa et al., 1978; Korn et al., 1982) and synaptic noise may dynamically influence the M-cell threshold (Hatta and Korn, 1999; Marti et al., 2008). Also, C-start latency was constrained to $<22 \mathrm{~ms}$, suggesting that an unidentified mechanism detects stimulus abruptness (Vu et al., 1997) and could account for the finding that escape probability for ramped sound waves was low relative to that reported for abrupt stimuli of equivalent intensity (Preuss and Faber, 2003).

\section{Potential algorithms for left-right sound source discrimination}

Identifying precisely how left-right sound source discrimination is achieved on the basis of the sound-evoked responses is problematic. Previous attempts to model the discrimination identified several algorithms based on the phase model that can successfully resolve the $180^{\circ}$ ambiguity in the M-cell system (Guzik et al., 1999). Our results confirm the viability of these models and nar- 
row the range of computational possibilities. However, because we did not use acceleration (Casagrand et al., 1999) or underwater sound stimuli, the specific solution remains speculative. Nevertheless, the results do implicate the involvement of excitatory-inhibitory integration at the $\mathrm{M}$-cell level. One potential algorithm is that the phase-locked EHPs and EPSPs preferentially encode pressure rarefaction and particle motion, respectively, and the integration of these two components solves the $180^{\circ}$ ambiguity problem (Fig. $7 A$ ). A similar computation could also occur by the coincidence of EPSPs in the lateral dendrite that encode the phase of the two components. Another potential algorithm (Eaton et al., 1995) is that a phase comparison between pressure and particle motion occurs in the PHP neuron (Fig. $7 B)$. In this case, the $\mathrm{M}$-cell responds primarily to sound pressure and phase comparison at the axon hillock is not required. Furthermore, binaural computations may occur in PHP neurons when fast EPSPs originating from the left and right sacculi coincide and summate and could be used to better resolve the axis of particle motion (Fay and Edds-Walton, 1997). Future investigations will likely refine these hypotheses and advance the concept of the M-cell as a neurobiological model for decision making (Korn and Faber, 2005).

\section{References}

Anderson DJ, Rose JE, Hind JE, Brugge JF (1971) Temporal position of discharge in single auditory nerve fibers within the cycle of a sine-wave stimulus: frequency and intensity effects. J Acoust Soc Am 49 [Suppl 2]:1131-1139.

Bakker MJ, van Dijk JG, van den Maagdenberg AM, Tijssen MA (2006) Startle syndromes. Lancet Neurol 5:513-524.

Bartelmez GW (1915) Mauthner's cell and the nucleus motorius tegmenti. J Comp Neurol 25:87-128.

Blaxter JHS, Gray JAB, Denton EJ (1981) Sound and startle responses in herring shoals. J Mar Biol Assoc UK 61:851-869.

Canfield JG, Eaton RC (1990) Swimbladder acoustic pressure transduction initiates Mauthner-mediated escape. Nature 347:760-762.

Canfield JG, Rose GJ (1996) Hierarchical sensory guidance of Mauthnermediated escape responses in goldfish (Carassius auratus) and cichlids (Haplochromis burtoni). Brain Behav Evol 48:137-156.

Carlson RW, Bradbury SP, Drummond RA, Hammermeister DE (1998) Neurological effects on startle response and escape from predation by medaka exposed to organic chemicals. Aquat Toxicol 43:51-68.

Carr CE, Friedman MA (1999) Evolution of time coding systems. Neural Comput 11:1-20.

Carr CE, Konishi M (1988) Axonal delay lines for time measurement in the owl's brainstem. Proc Natl Acad Sci U S A 85:8311-8315.

Carr CE, Konishi M (1990) A circuit for detection of interaural time differences in the brainstem of the barn owl. J Neurosci 10:3227-3246.

Carr CE, Heiligenberg W, Rose GJ (1986a) A time-comparison circuit in the electric fish midbrain. I. Behavior and physiology. J Neurosci 6:107-119.

Carr CE, Maler L, Taylor B (1986b) A time-comparison circuit in the electric fish midbrain. II. Functional morphology. J Neurosci 6:1372-1383.

Carr CE, Soares D, Parameshwaran S, Perney T (2001) Evolution and development of time coding systems. Curr Opin Neurobiol 11:727-733.
Casagrand JL, Guzik AL, Eaton RC (1999) Mauthner and reticulospinal responses to the onset of acoustic pressure and acceleration stimuli. J Neurophysiol 82:1422-1437.

Clopper CJ, Pearson ES (1934) "The use of confidence or fiducial limits illustrated in the case of the binomial." Biometrika 26:404-413.

Eaton RC, Popper AN (1995) The octavolateralis system and Mauthner cell: interactions and questions. Brain Behav Evol 46:124-130.

Eaton RC, Lavender WA, Wieland CM (1981) Mauthner-initiated response patterns in goldfish: evidence from simultaneous cinematography and electrophysiology. J Comp Physiol A Neuroethol Sens Neural Behav Physiol 144:521-531.

Eaton RC, Canfield JG, Guzik AL (1995) Left-right discrimination of sound onset by the Mauthner system. Brain Behav Evol 46:165-179.

Faber DS, Korn H (1982) Transmission at a central inhibitory synapse. I. Magnitude of unitary postsynaptic conductance change and kinetics of channel activation. J Neurophysiol 48:654-678.

Faber DS, Korn H (1989) Electrical field effects: their relevance in central neural networks. Physiol Rev 69:821-863.

Faber DS, Korn H, Lin JW (1991) Role of medullary networks and postsynaptic membrane properties in regulating Mauthner cell responsiveness to sensory excitation. Brain Behav Evol 37:286-297.

Fay RR (1984) The goldfish ear codes the axis of acoustic particle motion in three dimensions. Science 225:951-954. 
Fay RR, Edds-Walton PL (1997) Directional response properties of saccular afferents of the toadfish, Opsanus tau. Hear Res 111:1-21.

Fisher NI (1993) Statistical analysis of circular data. Cambridge, UK: Cambridge UP.

Furukawa T, Furshpan EJ (1963) Two inhibitory mechanisms in the Mauthner neurons of goldfish. J Neurophysiol 26:140-176.

Furukawa T, Ishii Y (1967) Neurophysiological studies on hearing in goldfish. J Neurophysiol 30:1377-1403.

Furukawa T, Hayashida Y, Matsuura S (1978) Quantal analysis of the size of excitatory post-synaptic potentials at synapses between hair cells and afferent nerve fibres in goldfish. J Physiol 276:211-226.

Guzik AL, Eaton RC, Mathis DW (1999) A connectionist model of left-right sound discrimination by the Mauthner system. J Comput Neurosci 6:121-144.

Hama K (1969) A study on the fine structure of the saccular macula of the gold fish. Z Zellforsch Mikrosk Anat 94:155-171.

Hatta K, Korn H (1999) Tonic inhibition alternates in paired neurons that set direction of fish escape reaction. Proc Natl Acad Sci U S A 96:12090-12095.

Heiligenberg W, Rose GJ (1985) Phase and amplitude computations in the midbrain of an electric fish: intracellular studies of neurons participating in the jamming avoidance repsonse of Eigenmannia. J Neurosci 5:515-531.

Hudspeth AJ, Corey DP (1977) Sensitivity, polarity, and conductance change in the response of vertebrate hair cells to controlled mechanical stimuli. Proc Natl Acad Sci U S A 74:2407-2411.

Jayne BC, Lauder GV (1993) Red and white muscle activity and kinematics of the escape response of the bluegill sunfish during swimming. J Comp Physiol A Neuroethol Sens Neural Behav Physiol 173:495-508.

Jefferys JG (1995) Nonsynaptic modulation of neuronal activity in the brain: electric currents and extracellular ions. Physiol Rev 75:689-723.

Karlsen HE, Piddington RW, Enger PS, Sand O (2004) Infrasound initiates directional fast-start escape responses in juvenile roach Rutilus rutilus. J Exp Biol 207:4185-4193.

Koch C (1999) Biophysics of computation: information processing in single neurons. New York: Oxford UP.

Korn H, Faber DS (1975) An electrically mediated inhibition in goldfish medulla. J Neurophysiol 38:452-471.

Korn H, Faber DS (1976) Vertebrate central nervous system: same neurons mediate both electrical and chemical inhibitions. Science 194:1166-1169.

Korn H, Faber DS (2005) The Mauthner cell half a century later: a neurobiological model for decision-making? Neuron 47:13-28.

Korn H, Mallet A, Triller A, Faber DS (1982) Transmission at a central inhibitory synapse. II. Quantal description of release, with a physical correlate for binomial $n$. J Neurophysiol 48:679-707.

Kozloski J, Crawford JD (1998) Functional neuroanatomy of auditory pathways in the sound-producing fish Pollimyrus. J Comp Neurol 401:227-252.

Lin JW, Faber DS (1988) Synaptic transmission mediated by single club endings on the goldfish Mauthner cell. I. Characteristics of electrotonic and chemical postsynaptic potentials J Neurosci 8:1302-1312.

Lombard R, Fay RR, Werner Y (1981) Underwater hearing in the frog Rana catesbeiana. J Exp Biol 91:57-71.

Marti F, Korn H, Faure P (2008) Interplay between subthreshold potentials and gamma oscillations in Mauthner cells' presynaptic inhibitory interneurons. Neuroscience 151:983-994.

Oda Y, Kawasaki K, Morita M, Korn H, Matsui H (1998) Inhibitory longterm potentiation underlies auditory conditioning of goldfish escape behaviour. Nature 394:182-185.

Pereda A, O'Brien J, Nagy JI, Bukauskas F, Davidson KG, Kamasawa N, Yasumura T, Rash JE (2003) Connexin35 mediates electrical transmission at mixed synapses on Mauthner cells. J Neurosci 23:7489-7503.

Popper AN (1977) A scanning electron microscopic study of the sacculus and lagena in the ears of fifteen species of teleost fishes. J Morphol 153:397-417.

Preuss T, Faber DS (2003) Central cellular mechanisms underlying temperature-dependent changes in the goldfish startle-escape behavior. J Neurosci 23:5617-5626.

Preuss T, Osei-Bonsu PE, Weiss SA, Wang C, Faber DS (2006) Neural representation of object approach in a decision-making motor circuit. J Neurosci 26:3454-3464.

Schuijf A (1975) Directional hearing of cod (Gadus morhua) under approximate free field conditions. J Comp Physiol A Neuroethol Sens Neural Behav Physiol 98:307-332.

Smith ZM, Delgutte B, Oxenham AJ (2002) Chimaeric sounds reveal dichotomies in auditory perception. Nature 416:87-90.

Szabo TM, Weiss SA, Faber DS, Preuss T (2006) Representation of auditory signals in the M-cell: role of electrical synapses. J Neurophysiol 95:2617-2629.

Triller A, Korn H (1981) Morphologically distinct classes of inhibitory synapses arise from the same neurons: ultrastructural identification from crossed vestibular interneurons intracellularly stained with HRP. J Comp Neurol 203:131-155.

Tuttle R, Masuko S, Nakajima Y (1986) Freeze-fracture study of the large myelinated club ending synapse on the goldfish Mauthner cell: special reference to the quantitative analysis of gap junctions. J Comp Neurol 246:202-211.

Viete S, Peña JL, Konishi M (1997) Effects of interaural intensity difference on the processing of interaural time difference in the owl's nucleus laminaris. J Neurosci 17:1815-1824.

Vu ET, Berkowitz A, Krasne FB (1997) Postexcitatory inhibition of the crayfish lateral giant neuron: a mechanism for sensory temporal filtering. J Neurosci 17:8867-8879.

Watanabe A, Takeda K (1963) The change of discharge frequency by A.C. stimulus in a weakly electric fish. J Exp Biol 40:57-66.

Weiss SA, Szabo TM, Faber DS, Preuss T (2005) Spectral analysis of sound evoked potentials in the Mauthner cell. Soc Neurosci Abstr 31:77.4.

Weiss SA, Zottoli SJ, Do SC, Faber DS, Preuss T (2006) Correlation of C-start behaviors with neural activity recorded from the hindbrain in free-swimming goldfish (Carassius auratus). J Exp Biol 209:4788-4801.

Weiss SA, Preuss T, Faber DS (2008) A role of electrical inhibition in sensorimotor integration. Proc Natl Acad Sci U S A 105:18047-18052.

Zottoli SJ (1977) Correlation of the startle reflex and Mauthner cell auditory responses in unrestrained goldfish. J Exp Biol 66:243-254.

Zottoli SJ, Faber DS (1980) An identifiable class of statoacoustic interneurons with bilateral projections in the goldfish medulla. Neuroscience 5:1287-1302. 